\title{
Student Collaboration in Hybrid Classrooms Using PBWorks: A Study of University Students in Najran, Saudi Arabia
}

\author{
Hadi Almonuf
}

\begin{abstract}
Modern classrooms are no longer always traditional, face-to-face settings. Many students take part in online classes and hybrid classes. Education technology has made it possible for students to learn anytime and anyplace, which can be critical if attending class is difficult. This quantitative study explored the use of the wiki tool PBWorks for group collaboration in a hybrid setting. The participants were students from two classes, each studying the same course with the same professor at the University of Najran in Najran, Saudi Arabia. There were 21 students in the control group and 19 students in the experimental group $(\mathrm{N}=40)$. Both classes split into small groups for collaborative projects, with the experimental group working online using PBWorks to collaborate. The study explored if there were any differences in academic achievement between groups and if there were any differences in students' attitudes toward collaboration. The results indicate that although both classes had similar improvement academically, the experimental group improved at a faster rate. Both groups showed an improvement in attitude toward collaborative learning, however there was no statistically significant difference between groups in pre-and post-survey or interaction between time and attitude.
\end{abstract}

Index Terms-Academic achievement, collaboration, education technology, PBWorks, wikis.

\section{INTRODUCTION}

The University of Najran was officially established in Najran, Saudi Arabia in 2006. The 2016 enrollment was 11, 917 students with 466 total staff [1]. Students at the University of Najran have been using Blackboard Learn for any online component of classes. Most classes have continued use traditional teaching methods, which means mostly face-to-face. Najran is the capital city in the Najran province and is located on the southern border with Yemen. At the time of the study, Houthi rebels held the capital city in Yemen and are at war with Saudi Arabia and other gulf countries. The city of Najran had been experiencing mortar attacks and long-range bombing by the rebels since March 2015 [2]. Because of the danger this poses, all of the schools in the southern part of the city had been closed and many people had been moved to the northern part of the city for their safety. Students were unable to attend regular classes and the best alternative was to encourage distance learning

Manuscript received January 16, 2018; revised February 26, 2018. This work was a partial requirement for the degree Doctor of Philosophy in Education Technology at the University of Northern Colorado and received no financial support by any organization or agency.

H. Almonuf was with University of Northern Colorado, Greeley, CO 80634 USA (e-mail: almo2005@bears.unco.edu). for those students who could not attend school, including university students. Unfortunately, many teachers and students have limited experience using the technology that is needed to conduct classes in this non-traditional way.

As part of the push to encourage distance learning, there has been some research into the effectiveness of blended learning, which incorporates using platforms such as Blackboard with the regular face-to-face classroom [3], [4]. Other research of education using Web 2.0 technology in Saudi Arabia has studied both student achievement and student attitudes [5]-[7]. Using the technology provided by Web 2.0 platforms, hybrid class environments can lead to an improved blended learning experience is using wikis to provide a method for students to collaborate, which can improve student learning. In Najran, a combination of war, lack of an understanding of technology, and instructors and students who are not willing to try new technology have demonstrated a need for studying how using technology can improve education.

The purpose of this study was to examine how students at Najran University, in Najran, Saudi Arabia, experience collaboration in different classroom environments. Students taking part in collaborative activities in face-to-face classes often show higher levels of academic achievement [5]. This study examined if students who use an easy to use wiki, in this case PBWorks, in a hybrid class for the same collaborative activities will demonstrate different academic achievement than in the face-to-face classroom.

The study also examined any changes in students' attitudes toward participating in collaborative learning experiences. If students have a positive attitude toward collaborative learning in a face-to-face classroom environment, it is hypothesized that students' attitudes toward using PBWorks in a hybrid class for the same collaborative activities will be more positive than those of the students in the face-to-face classroom.

A pre-test/post-test was used to compare academic achievement levels as demonstrated by average grades. A survey instrument of 25 questions was used to determine pre-and post-attitudes toward collaborative learning. The study was guided by two research questions.

RQ1. Will students experience statistically significant differences in academic achievement after participating in collaborative activities in a hybrid class compared with students participating in collaborative activities in a traditional face-to-face classroom?

RQ2. Will students experience statistically significant differences in attitudes toward collaborative learning after 
participating in collaborative activities in a hybrid class compared with students participating in collaborative activities in a traditional face-to-face classroom?

\section{LITERATURE}

It is important to understand the technology that is available and how it can be used in hybrid classes to create successful collaborative efforts. Web 2.0 tools can bring students together collaboratively as they construct new knowledge through social networking. Students gain much more control over the information and are no longer passively learning. They are actively teaching each other. Active participation, collaborative creativity, and socially constructing knowledge are all parts of creating critical, problem-solving thinkers [8]. Using Web 2.0 tools is not only new to both public and private universities in Saudi Arabia, it is seen as offering greater ability for interaction and more inclusive user experience. Such tools can be seen as transforming not only education in Saudi Arabia, but global education [7]. Wikis are one form of Web 2.0 tools. Anyone using a Wiki can become part of an online collaborative effort, which is why this is a valuable tool for university students.

Wikis can be used as part of required class assignments especially if the project is dependent on the group knowledge sharing [9]. The usefulness of the Wiki is important to collaborative projects so that students can offer peer reviews directly to the work, as well as offering suggestions and editing for each other's writing. How this is used in Saudi Arabia is relatively unknown. Using Wikis is another form of communication available to students that might not be willing to share and work together inside the classroom due to shyness or feeling awkward. The distance provided by interacting via Wikis can help students overcome some of these feelings of shyness. Also, according to Alzahrani [9], there are only about ten studies about the use of Wikis in Saudi Arabia. This indicates that more research on the effectiveness of using Wikis in Saudi schools is necessary.

Alshumaimeri [6] agrees about how effective Wikis can be for collaboration. Wikis are often only used to teach writing skills; however, the author suggests that teachers need to make sure that collaborative assignments need to lead to improved academic achievement. It is also important to realize that Wikis may change in nature as technology changes, so teachers and students need to work together to use technology in ways that continue to offer educational benefits.

By giving students a platform that is student-centered and self-directed, student interaction becomes an environment for real time problem solving. One concern for teachers who use group projects is when one member of a group does a majority of the work, another member does little, and the rest of the group agree with the leader. Wikis create more balance since each person's work is recorded and seen by the group, as well as by the teacher. Using the technology available to work together in teams creating work that demonstrates knowledge growth and academic achievement is gives strength to the collaborative nature of Wikis [6].

Education trends in higher education are leaning more towards how to establish best practices using computer technology in the classroom. Much of the technology is more learner-centered than much of the curriculum found in traditional lecture classes. Learner-centered and interactive curriculum can be an important way for universities to attract more international students and to become more globalized [10]. As technology has improved and more students have access to computers and the Internet, the use of wikis has become more accepted as a way to support how students learn. In a study by Davies [10], results indicated that the ways in which students constructed knowledge were better by using technology as a study strategy. The study also concluded that students' attitudes toward using technology as part of their education were also improved. Overall, students were much more likely to take more responsibility for their learning by using technology than in a traditional, lecture only classroom. Knowing this can help instructors design coursework that includes the use of technology, including Wikis, to improve student learning. Wikis can be helpful in putting together collaborative efforts for lessons or projects that can take the entire semester or school year. In this way, student achievement and student attitudes can be improved [10].

Collaboration is an essential format for bringing students together to interact without needing the constant presence of the teacher. Using collaborative efforts helps make using wikis easier and more appreciated by students [6]. Students are more likely to remain motivated to complete collaborative tasks for a wiki assignment. In this way, the act of learning is much more of a social interaction, which leads to greater opportunity for peer teaching and learning [11]. Domalewska [12] refers to collaborative learning as a kind of activity where students are encouraged to work together creating a social activity that is completely different from solo learning using practice exercises and memorization. A wiki is a technological tool that is an efficient environment for students to work collaboratively on analyzing and solving problems, as well as to offer each other educational support.

In the classroom, students often don't think they have the experience needed to share their opinions, especially if the technology involved is new to them [13]. What students who have not collaborated do not realize is that through collaboration, they are helping each other learn important concepts. When students with differing opinions share their ideas, they are helping each other construct new knowledge. All of this helps bring the community of collaborators together to create a social learning environment [14]. As Whitney and Smallbone [14] point out, this experience in the school setting produces valuable experience of how teams in professional settings actually work together. Teachers who want to introduce collaboration using technology need to remember that there can be problems working online that students might not have in a regular face-to-face classroom. Teachers need to make sure to design projects that help students maintain respect when making comments on others' work or editing each other. The challenges can be overcome through patience and good curriculum design [14].

Although research of hybrid classes, or blended learning, is limited in Saudi Arabia, it is encouraging that the Ministry of Saudi Higher Education created a National Plan for 
Information Technology, which encourages e-learning, including blended learning [15]. This encouraging effort has given Saudi universities more opportunity to develop distance technology and blended learning opportunities for more students. According to Alebaikan [15], the King Fahad University of Petroleum and Minerals and King Khalid University have recently begun putting together curriculum for the addition of blended learning classes.

As the literature suggests, using Wikis such as PBWorks in classroom settings can provide a platform for improving student collaboration on projects. Without the creation of Web 2.0, wikis would not be possible. As more university courses will be offered either completely online or in a hybrid format, knowing how to use the tools available becomes more important. Instructors who have experience using collaboration as a strategy for student achievement and enhanced student learning know the difference collaborative projects can make. This study is concentrating on discovering if using a Wiki platform such as PBWorks as a collaborative tool in a hybrid setting will have a positive effect on student achievement. There is evidence that collaboration also leads to higher levels of student satisfaction, which this study measured. The lack of research in Saudi Arabian university settings indicates the need for this and other similar studies, especially as universities encourage more online learning.

\section{METHOD}

\section{A. Study Design}

This quantitative study was designed as an experiment to understand the effects of students using PBWorks in a hybrid setting. For this experiment, the control group of students used collaborative strategies within a traditional face-to-face classroom, while the experimental group used collaborative strategies using the PBWorks wiki tool in a hybrid class setting. The design included the use of pre-test - post-test to establish student achievement within the class and the use of a pre- and post - surveys to examine student attitudes toward using PBWorks as a collaboration strategy within a hybrid setting. Using this pre- and post-test method offered some control over extraneous variables. This was important since the selection of participants was not truly random.

\section{B. Participants and Setting}

Participants for this study were current students in two identical courses at Najran University. There was a total of 40 $(N=21$ and $N=19)$ students chosen from two classes that were in session at the time of the study. The participants ranged in age from 18 to 25 and were all male. Although the study used the course curriculum, all participation in the study survey was voluntary and not participating in the study did not affect any participant's grade in the course. Convenience sampling was used because the researcher needed to have two nearly identical classes studying the same course material taught by the same professor at the same time. The participants were in either the control group or the experimental group depending on which class was chosen to have a collaborative only assignment in a traditional face-to-face setting and which class was chosen for the hybrid class that used the PBWorks wiki (the experimental group). The students were all in one of two Integrating Technology in Education courses taught by the same professor.

The setting was two classrooms at the University of Najran. The professor teaching the course randomly chose which classroom would be used as the control group and which would be the experimental group.

\section{Learner's Handout}

To assist the participants in the hybrid class, the researcher provided a learner's handout that discussed how to use PBWorks. This was made available at the beginning of the semester in which the study was conducted. Included in the handout were instructions for the basic operation of PBWorks, including: creating an account and setting up login information; details on security; managing wiki workspaces, pages, and files; and creating and uploading new files. The handout was to help the students become familiar with PBWorks and to have a visual aid they could refer to from time to time for assistance. Although the screenshots were in English, PBWorks now supports Arabic in its workspaces. The information on each screenshot was accompanied with an Arabic translation.

\section{Instruments}

Two instruments were used in this study. The first instrument consisted of two academic tests of the course material designed by the course instructor. Since the academic tests were administered by the course instructor for previous courses, the process was used with assurance for this study. The second instrument was a 25-question survey of student attitudes toward collaborative learning. How both of these instruments were administered to each group is explained in the procedures. Both groups were given identical instruments.

The questionnaire for this study was adapted from a study of collaborative learning in an asynchronous collaborative learning [16], [17]. The results of testing the questionnaire show high reliability and validity. For this study, a copy of the questionnaire translated into Arabic was administered to the participants. A five-point Likert scale was used for responses: strongly agree; agree; neither agree nor disagree; disagree; and strongly disagree.

The 25 questions on the questionnaire were designed to measure students' experiences with collaborative learning and were broken into six variables. Table 1 explains the six variables, how many questionnaire items are used for each variable, and the Cronbach's alpha for each measure [16].

\begin{tabular}{lcc}
\multicolumn{3}{c}{ TABLE I: STUDENTS' EXPERIENCES WITH COLLABORATIVE LEARNING } \\
\hline \hline Variable & Number of Items & Cronbach's alpha \\
\hline Monitoring working procedures & 8 & 0.87 \\
Participation & 5 & 0.85 \\
Monitoring group progress & 5 & 0.83 \\
Helping each other & 3 & 0.70 \\
Giving feedback & 2 & 0.75 \\
Need to be monitored & 2 & 0.68 \\
\hline \hline
\end{tabular}

\section{E. Procedure}

Participants were members of one of two classes being 
taught by the same instructor using the same course material. One class was the control group, which was a face-to-face class and did not use the PBWorks wiki to do the collaborative assignment as part of this research. The experimental class was a hybrid class doing some of their course work online, including the collaborative assignment using the PBWorks wiki as part of this research. Both groups received the same type and amount of course information.

At the beginning of the semester, the instructor explained that part of the course would include a collaborative, small group assignment. The course would otherwise be taught in the same format the instructor has previously used. In both classes, students took a test following the first segment of lessons, which took place in the third week of the semester. The results of this first test was used as a baseline for academic achievement.

At that point in the course, the instructor introduced the collaborative assignment to both classes. For the assignment, each class was broken into small groups of four or five students. The instructor provided written instructions for the collaborative assignment. The control group class (Group 1) did the collaborative work only while in the classroom. Individual students were allowed to work on their own outside of the classroom and bring material to class to share with their groups, but the group work took place only during classroom time. The experimental group class (Group 2) did the collaborative work using only a PBWorks platform and worked on the assignment at any time. The instructor allowed students in Group 2 to work together in groups in the computer lab for a minimum of one class period per week. Students in Group 2 were allowed to work in the computer lab at their convenience outside of class. They could also work on personal computers at home if possible. The assignment took both classes approximately four weeks to complete. I worked with the instructor to make sure the students in Group 2 knew how to use the PBWorks wiki. The instructor and I set up a secure PBWorks account for Group 2 to use.

At the beginning of the experiment, all of the students in both classes were given the 25-question survey asking their perceptions of collaborative work. The questions on the survey were designed to weigh students' perceptions of six variables. The results of this first survey was then compared with the results of the same survey that was given to the students at the end of the assignment to measure if students' attitudes toward collaboration changed. Then the results of the survey of Group 1 were compared with the results of the survey of Group 2 to measure if there was a difference in students' attitudes between the two classes.

Following the completion of the collaborative assignment, the instructor gave an academic exam based on the learning goals of the assignment. The results of this test were compared with the results of the first exam to measure if using collaboration as a strategy changes academic achievement. Then, the results of the second exam from Group 1 were compared with the results of the same exam from Group 2 in order to measure if using PBWorks changed academic achievement more than using only in-class collaboration.

The instructor of the course administered the academic tests. Before the students took the survey, the instructor explained that taking part in the survey did not affect students' grades in any way. The instructor also explained that students must not put their names on the forms and that their names would never be used in any of the information collected. A research assistant handed out and collected the surveys from students during the class period. The envelopes used to collect the surveys were marked as "Group 1" and "Group 2". The assistant did not show the surveys to the instructor at any time, but delivered them to the researcher.

The instructor allowed the participants to know that their grades were not dependent on their participation in this research. If at any time the instructor determined that this study was detrimental to the participants or was interfering with their progress in the course, the instructor could have stopped the study.

No identifying information was attached to any of the documents or transcripts. All survey result information was maintained in a password protected, encrypted computer file available to the researcher. No identifying information was made available to the researcher at any time. When the preand post-test of the questionnaires were administered, the instructor explained the procedure to the students. Then, an assistant handed out the questionnaires. When students finished, the questionnaires were collected into an envelope that was sealed and then delivered to the researcher. The researcher randomly assigned alpha/numerical identifications for each questionnaire.

\section{F. Data Analysis}

Data analysis for this study was completed using SPSS 20.0 software. There was one dependent variable (test scores) in the first research question and one independent variable with two levels, an experimental group and a control group. There were six dependent variables for the second research question: 1) how working procedures are monitored; 2) levels of participation; 3) willingness to help each other; 4) how group progress is monitored; 5) feedback; and 6) the perceived need for monitoring. As with the first research question, there was one independent variable with two levels, an experimental group and a control group. The alpha level for this study was set at 0.05. A two-way ANOVA was used on the data for both research questions.

\section{RESULTS}

The following are the results of the data/statistical analyses that were performed to answer the research questions regarding students' collaborative experiences, academically and attitudinally, in either a traditional (face-to-face) or hybrid (face-to-face and online) in an undergraduate course, Integrating Technology in Education, at Najran University in Saudi Arabia. Academic performance was defined by pre-and post-tests that were assessed by the same instructor for both groups. Attitude toward collaboration was defined in this dissertation, according to a survey that was developed by Dewiyanti, Brand-Gruwel, Jochems, and Broers in 2007 [16], and translated into Arabic for a similar subset of students in Kuwait [17]. 


\section{A. Assumptions}

The purpose of conducting a two-way mixed ANOVA is to compare the mean differences between groups, especially when determining if there are differences between independent groups over time. It is also important to discover if there is any interaction between variables on the dependent variable. This two-way mixed ANOVA has one between-subjects factor and one within-subjects factor for each research question.

Of the assumptions for the ANOVA, the first assumption states that one dependent variable is measured at a continuous level, for example academic achievement or attitude. The second assumption that there is one between-subjects factor, or independent variable, that is categorical with two or more categories. The categorical variable is measured on a Likert scale. The 25 survey questions concerning attitude were broken into six categories Monitoring working procedures, participation, monitoring group progress, helping each other, giving feedback, and need to be monitored (See Table I). The participants in Group 1 and Group 2 were considered unrelated.

The within-subjects factor that was categorical were related because the participants were measured on the same dependent variables at the same time points and under the same conditions, in this case class_id and time. The results indicated that there were no significant outliers in any cell of the design. Lavene's test for equality of variances tested the variance of the dependent variable to make sure it was equal between the groups. To show that the covariances were consistent, Boxes test of equality of covariance matrices was used. Mauchly's test of sphericity showed that the variance of differences between groups was equal. All of the essential assumptions of the ANOVA were met. The following results were obtained as they relate to each of the research questions.

\section{B. Research Question One}

The first research question asked: Will students experience statistically significant differences in academic achievement after participating in collaborative activities in a hybrid class compared with students participating in collaborative activities in a traditional face-to-face classroom?

The answer is, yes, in a certain way. Fig. 1 displays the data generated by SPSS in a $2 \times 2$ factorial mixed design in response to this question. Overall, students in both classes demonstrated academic achievement, as they collaborated in their group projects. While the two groups were not significantly different at either the beginning or the end, there was a statistically significant difference in the rate of progress in achievement.

Table II presents the descriptive statistics regarding the pre-and post-test results for both groups achievement scores. There are minimal differences between the test scores of the two groups; but, the increase in the mean between the pre-test and the post-test for Group 2 shows a greater increase than for Group 1.

The hybrid group went from a lower score to a higher score at a faster rate than the traditional group of undergraduate students. This rate is demonstrated in Fig. 1.

The final comparative outcome showed that the two groups realized similar academic achievement. Yet, despite starting at a slightly lower but not statistically significant academic achievement level, students from the hybrid group finished the course at a nearly equivalent level. Ultimately, the analysis showed a statistically significant interaction between the intervention (traditional vs. hybrid collaboration) and time on the projects.

TABLE II: MEAN BETWEEN GROUPS' ACHIEVEMENT — DESCRIPTIVE STATISTICS

\begin{tabular}{llccr}
\hline \hline & $\begin{array}{c}\text { class_id } \\
\text { (Groups) }\end{array}$ & Mean & $\begin{array}{c}\text { Std. } \\
\text { Deviation }\end{array}$ & $\mathrm{N}$ \\
\hline $\begin{array}{l}\text { (Groups) } \\
\text { Pre-Test for }\end{array}$ & 1 & 77.90 & 13.849 & 21 \\
Achievement & 2 & 68.00 & 18.714 & 19 \\
& 1 & & & 21 \\
Post Test for & 1 & 87.90 & 7.886 & 19 \\
Achievement & 2 & 86.63 & 5.659 & \\
\hline \hline
\end{tabular}

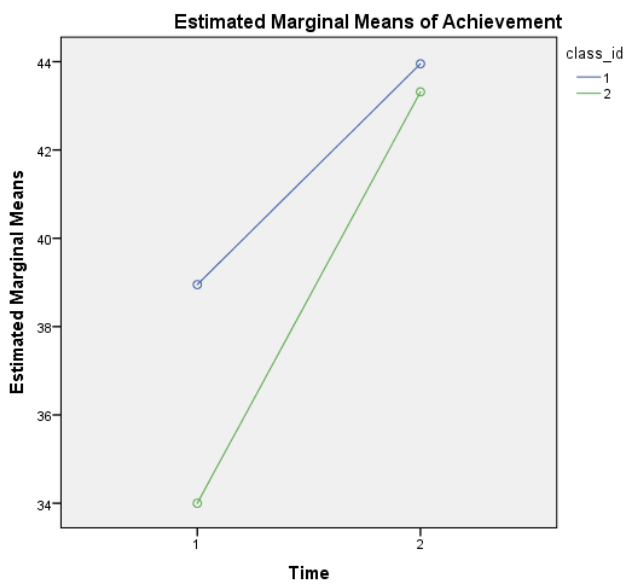

Fig. 1. Achievement between traditional and hybrid pre-and post-tests.

\section{Research Question Two}

Research question two asked: Will students experience statistically significant differences in attitudes toward collaborative learning after participating in collaborative activities in a hybrid class compared with students participating in collaborative activities in a traditional face-to-face classroom?

The answer is, no. The determination of significant difference between groups 1 and 2 in terms of collaborative attitude was based on pre-and post-survey results that were collected before and after the intervention of implementing a collaborative project in each group.

Table III presents the descriptive statistics regarding the pre-and post-test results for both groups, separately. There are minimal differences between the scores of the two groups, based on a Likert scale for both for pre-and post-tests; but, there is an increase in mean for between the groups' post-test results.

The traditional and hybrid classes (class_id) revealed no significant difference regarding the average attitude of the students in either class. There is a marginal difference between students' attitudes. Those in the hybrid class ranked a higher means in terms of positivity toward collaboration in the group project. 
The following diagram (see Fig. 2) demonstrates students' attitude clearly showed that there was no significant difference between the traditional and hybrid groups at the beginning, as well as at the end of the courses. Furthermore, the rate of growth for both groups was similar. Therefore, there was no statistical difference between groups in pre, post or interaction (time and attitude).

TABLE III: MEAN BETWEEN GROUPS' ATTITUDE TOWARD COLLABORATION - DESCRIPTIVE STATISTICS

\begin{tabular}{|c|c|c|c|c|}
\hline & class_id & & Std. & \\
\hline & (Groups) & Mean & Deviation & $\mathrm{N}$ \\
\hline \multirow{3}{*}{$\begin{array}{l}\text { Pre-Test for } \\
\text { Attitude }\end{array}$} & 1 & 3.331 & .34966 & 21 \\
\hline & 2 & 3.509 & .80464 & 19 \\
\hline & Total & 3.416 & 60797 & 40 \\
\hline \multirow{3}{*}{$\begin{array}{l}\text { Post Test for } \\
\text { Attitude }\end{array}$} & 1 & 4.213 & .56219 & 21 \\
\hline & 2 & 4.326 & .39130 & 19 \\
\hline & Total & 4.267 & .48581 & 40 \\
\hline
\end{tabular}

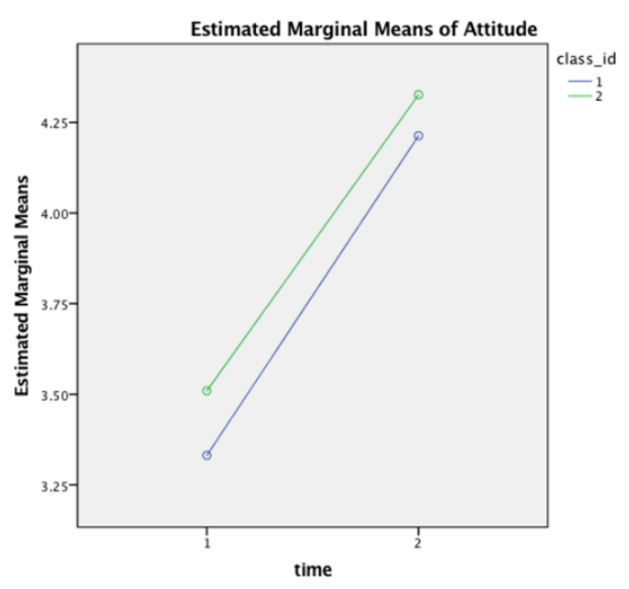

Fig. 2. Estimated marginal means of attitude.

\section{DISCUSSION}

The purpose of this study was to examine how students at Najran University, in Najran, Saudi Arabia, experienced collaboration in different classroom environments. This study examined if students who used PBWorks in a hybrid class for the same collaborative activities demonstrated higher academic achievement than in the face-to-face classroom. The study also examined if there were changes in students' attitudes toward participating in collaborative learning experiences. The students were all in one of two Integrating Technology in Education courses taught by the same professor. A comparison was made between students in the traditional (face-to-face) class and students in the hybrid class. Included here are the findings based on the two research questions; the limitations of the study; and the implications of the study. Finally, there is a discussion of recommendations for future research and educational applications in e-learning.

\section{A. Research Question One}

The first research question concerns students' academic achievement. The classes were Group 1 (the control - traditional group) and Group 2 (the experimental - hybrid group). Each group was given a pre-test before being introduced to collaborative learning and a post-test at the end of the experiment. The statistical analysis between groups indicates that students in both classes demonstrated academic achievement after collaborating in group projects. Both groups showed no statistically significant difference at either the beginning or the end of the experiment. However, there was a statistically significant difference in the rate of progress in achievement. The hybrid group went from a lower score to a higher score at a faster rate than the traditional group.

Both groups had nearly identical academic achievement levels before the collaborative group work was introduced, although the hybrid group was slightly, but not statistically significantly lower than the traditional group. Following the project, the hybrid group finished the course at nearly the same level as the traditional group. Since the analysis showed a statistically significant interaction between the intervention and time, this indicates that using PBWorks helps students achieve academically at a faster rate than not using an online collaborative tool.

There are possible reasons that the hybrid group was able to achieve at a faster rate based on their use of PBWorks. Using a Wiki both in and out of the classroom allows students to communicate with each other at any time, whereas students working in groups in traditional classrooms are generally limited to conversations that only take place in the classroom. Students working online also had more access to online resource materials that they could access at any time and from any place. This gives students in a hybrid setting an advantage of doing work when and where they choose instead of waiting to meet in the classroom [18].

Another advantage is how students from one group could write on another student's group page because they shared a common workspace and discussion board. The students in the traditional class did not have access to other group's ideas and discussions. Discussions between students has been shown to help students understand material presented in the classroom [19]. As a final advantage, PBWorks and other online Wiki tools offer online access to additional resources such as links to videos, images or pictures, and other documents that students sitting in a traditional classroom do not have.

\section{B. Research Question Two}

The second research question concerns students' attitudes toward working in collaborative groups. Analysis of responses to a 25-question pre-and post-survey were completed to determine any statistically significant difference in attitudes between the traditional group and the hybrid group before and after they had completed working in collaborative groups.

When the data were analyzed between subjects, it was found that attitudes changed linearly over time, indicating cause and effect between the introduction of collaborative projects and a change in attitude. However, since there was no linear change for the term of the experiment, attitude remained independent whether the students were in the control or the experimental group. The average measure of 
attitude was not significantly different between groups or between the average attitudes of the students in either class. It is the estimates of time that are different.

The data analysis clearly showed that there was a change in attitude over time. However, since there was no significant difference between groups at either the beginning or the end of the course and the rate of growth for both groups was similar, there was no statistically significant difference between groups in pre-and post-survey or interaction between time and attitude.

Prior to this study, none of the students in either group had participated in group collaboration. They had not realized how much they could learn from each other by working in groups. As Whitney and Smallbone [14] pointed out, students working in collaborative groups are actually creating a new learning environment that encourages the construction of new information. In this study, students in both classes found the experience favorable. As Kear, Donelan, and Williams [19] suggest, using a wiki in an online forum can be especially beneficial. When students realize that they are creating their own working environment that they can all see, they tend to become more engaged in the process with less need for monitoring by the instructor. This can "support a learner-centered pedagogy and foster self-regulated learning" [20]. Elgort, Smith and Toland [21] discussed many elements necessary for collaborative learning to be successful. This included how collaboration encourages "positive interdependence" (197) that can be particularly useful for students who are unable to meet face-to-face. This interdependence was a new idea for the two groups in this study at the University of Najran.

An important factor the data did not particularly measure was the effect of war on students' ability to regularly attend classes and how using technology can offer an effective alternative to attending the traditional, face-to-face class. Carpenter [22] relates how Saudi Arabia closed schools for weeks during 2004 in response to threats of terrorist activities. When schools are closed in emergency or ongoing situations, such as the current war with Yemen, being able to access information from a distance takes on a level of importance that can be beneficial for students who are sheltering away from the effects of the situation. This can be seen today in Najran, where military actions continue to threaten schools every day. During the gathering of the data for this study, classes were being held at the University with the understanding that bombing could have happened at any time.

\section{Limitations}

There are always limitations to quantitative studies including generalizable sample issues, including generalizability. This study is no different in that there were limitations beyond the control of the researcher. The first limitation concerned the selection of the sample. The researcher used convenience/criteria sampling rather than truly random sampling. It is true that the researcher did not know what course and professor would be chosen by the authorities at the University, but the sample did need to meet specific criteria, including that the two classes needed to be similar in size, be the same subject (course level and material), and be taught by the same professor. The class chosen to be the control group was a random selection made by the professor. A second sample issue concerned sample size. The control group was larger $(N=21)$ than the experimental group $(N=19)$ meaning that the total population was only 40 students. Gender is another issue in that all the students were male. It is difficult to generalize the results to larger populations based on small sample size and limited gender.

Two limitations completely outside the control of the researcher include the limited knowledge of the professor and the students in using technology. Much of the technology available at Najran University is new. Both professors and students in this study showed some resistance to using new technology. A second limitation for this particular study was that students had a difficult time connecting to the Internet using Wi-Fi. This was due to the effects of the current military conflict, which limited the strength and availability of Wi-Fi connectivity.

\section{Implications}

This study demonstrated that using online resources, such as PBWorks can make a difference in how quickly students achieve academically. This could have an impact on schools that are building a greater online presence or on course material taught in a hybrid environment. Professors considering the design of their courses might come to realize that allowing students to learn from each other and to access more information online saves valuable classroom time. Students can become better at self-regulated learning by becoming more familiar with using online resources. They may learn the importance of learning from fellow students as well as learning from the professor and the textbook. Since education technology is continuing to advance, it is important for educators to learn the value of incorporating the technology into the curriculum.

\section{E. Recommendations for Future Research}

Although it is important for educators to learn more about how technology can be used, more research into what types of technology works best is needed. This study is a replication of another study done in Kuwait [17]. In both studies, the sample sizes are small and limited by gender. Other researchers can follow the procedures found in this study to discover if the results would hold up in other circumstances. Only when enough studies have been done on the use of wikis for group collaboration can there be enough verification to support using wikis as an evidence-based best practice.

The Kuwaiti study [17] was conducted with only female students and this current study was conducted with only male students. Research of co-ed classes might be another important area for research to discover if there is a difference in results based on gender. Other different forms of this study might include online only courses rather than hybrid courses and testing high school or graduate students. It would be interesting to discover teacher attitudes as well as student attitudes, which could be an addition to the research.

Colleges and universities looking for best practices in online environments should consider using technology after it has been tested to find how well it works. Research needs to 
continue into those areas that are the most effective for student learning. Academic achievement is not the only determination of student success. It is important to continue to discover how students feel about using the technology.

\section{CONCLUSION}

The researcher for this study was concerned with two major questions. The first question was to determine what if any differences exist on the effect on academic achievement between two different class environments: a traditional, face-to-face classroom and a hybrid class using the wiki tool PBWorks. The second question was to investigate if there is any effect on students' attitudes toward collaborative learning based on these two class environments.

The results of the study indicated that there was a significant difference in academic achievement based on the variable of time. Both groups showed about the same levels of academic achievement, but the hybrid group that used PBWorks improved at a faster rate than the face-to-face group. Students' attitudes toward learning in collaborative groups showed no statistically significant differences between the groups either before or after the experiment. However, the results indicate that the improvement in attitudes in both groups is related to the introduction of working in collaborative groups, regardless of the environment.

Using PBWorks had a positive effect on academic achievement and working in collaborative groups had a positive effect on students' attitudes toward working collaboratively. It is possible that using any wiki platform in a hybrid setting might have positive effects on academic achievement. The finding that working collaboratively is met with positive attitude is encouraging. Students learning from each other can only reinforce what instructors are working at every day. Finding ways to help students use technology and to learn in any environment at any time is an important aspect of the future of education technology. With the concerns of trying to continue education efforts in war zones, in places where students are unable to travel to schools, and in situations where students might not be able to afford attending school, finding best practices in the use of education technology is vital.

\section{REFERENCES}

[1] Kingdom of Saudi Arabia (KSA). Ministry of Education, Higher Education. [Online]. Available: http://he.moe.gov.sa/en/studyinside/Government-Universities/Pages/N U.aspx

[2] Saudi Arabia escalates its military campaign. 10 Sep 2015. The Economist. [Online]. Available: http://www.economist.com/news/middle-east-and-africa/21663988-ye men-descending-prolonged-uncontrollable-war-saudi-arabia-escalates -its-military

[3] R. A. Alebaikan, "The future of blended learning," World Academy of Science, Engineering and Technology, vol. 63, pp. 484-488, 2012.

[4] A. A. Al-Qahtani and S. E. Higgins, "Effects of traditional, blended and e-learning on students' achievement in higher education," Journal of Computer Assisted Learning, vol. 29, no. 3, pp. 220-234, 2013.

[5] F. N. Al-Fahad, "The learners' satisfaction toward online e-learning implemented in the College of Applied Studies and Community Service, King Saud University, Saudi Arabia: Can e-learning replace the conventional system of education?" Turkish Online Journal of Distance Education, vol. 11, no. 2, 2010.

[6] Y. Alshumaimeri, "The effects of wikis on foreign language students writing performance," Procedia-Social and Behavioral Sciences, vol. 28, pp. 755-763, 2011.

[7] M. Aqil, P. Ahmad, and A. Hussain, "Use of web 2.0 in Saudi Arabia universities," International Journal of Information Dissemination and Technology, vol. 3, no. 3, pp. 158-166, 2013.

[8] L. Adcock and C. Bolick, "Web 2.0 tools and the evolving pedagogy of teacher education," Contemporary Issues in Technology and Teacher Education, vol. 11, no. 2, pp. 223-236, 2011.

[9] I. Alzahrani, "Evaluate wiki technology as e-learning tool from the point view of Al-Baha University students: A pilot study with undergraduate students in both faculties of Science and Education," Online Submission, 2012.

[10] A. Davies, "Integrating e-learning to improve learning outcomes," Planning for Higher Education, vol. 42, no. 4, pp. 23-29, 2014.

[11] L. Vygotsky, Interaction between learning and development. From: Mind and Society, Cambridge, MA: Harvard University Press, 1978, pp. 79-91.

[12] D. Domalewska, "Technology-supported classroom for collaborative learning: Blogging in the foreign language classroom," International Journal of Education \& Development Using Information \& Communication Technology, vol. 10, no. 4, pp. 21-30, 2014.

[13] G. P. Price and V. H. Wright, "Aligning web-based tools to the research process cycle: A resource for collaborative research projects," Journal of Interactive Online Learning, vol. 11, no. 3, pp. 121-127, 2012.

[14] D. Whitney and T. Smallbone, "Wiki work: can using wikis enhance student collaboration for group assignment tasks?" Innovations in Education and Teaching International, vol. 48, no. 1, pp. 101-110, 2011.

[15] R. A. Alebaikan, "Perceptions of blended learning in Saudi universities," Doctoral dissertation, University of Exeter, 2010.

[16] S. Dewiyanti et al., "Students' experiences with collaborative learning in asynchronous computer-supported collaborative learning environments," Computers in Human Behavior, vol. 23, no. 1, pp. 496-514, 2007.

[17] A. Y. A. A. A. Ibrahim, "The effects of using PBWorks in a hybrid collaborative class environment on students' academic achievement (Order No. 3453907)," Available from ProQuest Dissertations \& Theses Global; ProQuest Education Journals, 2011.

[18] J. L. Globokar, "Introduction to online learning: A guide for students," Sage, 2010.

[19] K. Kear, H. Donelan, and J. Williams, "Using wikis for online group projects: Student and tutor perspectives," International Review of Research in Open and Distance Learning, vol. 15, no. 4, 2014.

[20] N. Dabbagh and A. Kitsantas, "Personal Learning Environments, social media, and self-regulated learning: A natural formula for connecting formal and informal learning," The Internet and Higher Education, vol. 15 , no. 1, pp. 3-8, 2012.

[21] I. Elgort, A. G. Smith, and J. Toland, "Is wiki an effective platform for group course work?" Australasian Journal of Educational Technology, vol. 24 , no. 2,2008

[22] D. Carpenter, "Surviving crisis mode," Learning \& Leading with Technology, vol. 32, no. 8, pp. 12-14, 2005 .

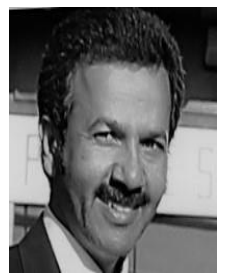

Hadi Almonuf was born in Saudi Arabia in 1973. His current family home is in Najran. He currently resides with his wife and children in Greeley, Colorado while his wife pursues her Ph.D. He earned a Ph.D. in Education Technology from the University of Northern Colorado, Greeley, Colorado, USA in 2017, a Master of Arts from the University of Northern Colorado, Greeley, Colorado, USA in 2011, and Bachelor of Arts, Geography from King Khalid University, SA in 2002.

Dr. Almonuf's dissertation was nominated for an Award of Excellence in Education Technology from the University of Northern Colorado (UNC) For the academic year 2013-14, he received a Certificate of Appreciation from the Saudi Arabian Cultural Mission (SACM) and the UNC Students Club. He was awarded an Academic Excellence Award from the Department of Education Technology of the University of Northern Colorado in 2011. He served as the President of the Saudi Club at the University of Northern Colorado in 2009 and 2010. Dr. Almonuf is a member of the Association for Talent Development, Teacher Training and Education, Technology in Education (TechInEDU), International Society for Technology in Education (ISTE), and the Association for Educational Communications and Technology (AECT). 